\title{
Acceptance of Hybrid sperm Indian Male Less sunlight pharmacy Institutions in Indian University India keep woman happy in bed privately
}

\section{Rahul Hajare}

Adviser Ishwar Deshmukh Institute of Pharmacy, ICMR NARI PDF, National AIDS Research Institute, Indian Council of Medical Research Institute, New Delhi.

* Corresponding Author: Rahul Hajare, Adviser Ishwar Deshmukh Institute of Pharmacy, ICMR NARI PDF, National AIDS Research Institute, Indian Council of Medical Research Institute, New Delhi.

Received Date: January 08, 2021; Accepted Date: February 08, 2021; Published Date; February 13, 2021.

Citation: Rahul Hajare, (2020). Acceptance of Hybrid sperm Indian Male Less sunlight pharmacy Institutions in Indian University India keep woman happy in bed privately. J. Clinical Research Notes. 2(1). Doi: 10.31579/2690-8816/030

Copyright: (c) 2021 Rahul Hajare, This is an open-access article distributed under the terms of the Creative Commons Attribution License, which permits unrestricted use, distribution, and reproduction in any medium provided the original author and source are credited.

\section{Abstract}

Turns out, women have more diverse preferences related to sexual pleasure than believed. A finding from zero child Indian couple focused on orgasm and sexual pleasure as related to genital touch and stimulation. There has been little known at the population level about detailed aspects of women's sexual pleasure and orgasm.

Keywords: hybrid sperm; population level; women's sexual pleasure; orgasm

\section{Executive Summary}

Hybrid sperm has accepted. Tongue has the strongest muscle body it has definitely one of the most unique: The tongue can be a harbinger for the health of your entire body. According to researcher tongue and mouth tissues are more transparent than skin in the game so medical providers can more easily see signs of a medical condition beneath the surface [1]. The tongue and mouth have a great place to look for signs of disease before a patient develops symptoms tongue has loaded with sensory nerves, making it more sensitive than other parts.

\section{Introduction}

Most previous studies utilised clinical, college and convenience samples from Pharmaceutical Instituions. Researcher worked to change that with this research and provide data surveying a nationally representative probability sample of adult women. Researcher team conducted the study with a focus on discovering a greater understanding of women's sexual pleasure and orgasm [2]. The study results challenge the mistaken, but common, notion that there have universal sex moves that work for everyone. On the other hand, the data also make clear that there have certain styles of touch that are more commonly preferred by women, emphasising the value of studying sexual pleasure and not just sexual problems. The study found that the more than 50 women, between 18 to 94 years of age including widow, surveyed reported a diverse set of preferences for genital touch, location, pressure, shape and pattern [3]. Further, 41 per cent of women preferred just one specific style of touch, underscoring the value of couples having conversations about their preferences and desires. This study provides the first Indian nationally representative data on pathways to orgasm during intercourse. Nearly 75 per cent of women reported that clitoral stimulation has either necessary for their intercourse orgasms, or helped their orgasms feel better. 18 percent noted that vaginal penetration alone has sufficient for orgasm [4]. The study has published in the same author.

\section{Discussion}

Happy sex life. Happy employees. Increase the productivity. The 'feel good' factor from having good sex can last you 12 hours! Want to stay happy and perform better at work? Start performing better in bed, as a study reveals, workers who had sex the night before are doing better at their jobs the next day. According to researchers from Pune University a happy sex life boosts their own job satisfaction which, in term of clean drinking water, clean toilets, clean laboratory basin, clean dress up, sufficient drinking water, enough light in class rooms, gives them a better work-life balance [5]. They came to work happier and more fulfilled, immersed themselves more in the tasks they have given and enjoyed their job more as a result, researcher is associate professor affiliated pune university. Rahul Hajare. We make jokes about people having a 'spring in their step,' but it turns out this is actually a real thing and we should pay attention to it," researcher explained. Sexual intercourse triggers the release of dopamine, a neurotransmitter associated with the reward centres in the small brain, as well as oxytocin, a neuropeptide associated with social bonding and attachment. The 'feel good' factor from sex lasts for approximately 12 hours win the weekly academic work load. The team looked at 1.5 married employees from an unnamed office-based business, monitoring their work performance and their sex habits. Those who had sex with their partners, at only home, performed their work tasks better the next day than those who did not have sex. They found that maintaining a healthy relationship that includes a healthy academic result will help 
employees stay happy, engaged in their work, reduce the hunger of sex in working place, which benefits the employees and the organisations they work for various project. In contrast, sacrificing sex in order to work is only likely to lower any feel good factor and raise levels of stress and darkness. This is a reminder that sex has social, emotional and physiological benefits, and it is important to make it a priority. Just make time for it," researcher explained.

\section{Conclusion}

In this work, by considering the problems of zero child couple has degeneration of sperm and it has not good news for shorter people. Researchers at studied people and found a link between bodily size and the number of previous sexual partners. Researcher found that taller guys tend to get more action. On the other hand, men who were shorter than average had one to three fewer sexual partners than the larger men. And the shortest men had the least previous bedroom encounters. Important findings show how important height has when it comes to the 'mating market. They reckoned that women might have a minimum height in mind when looking for male suitors. Researcher has repeatedly shown that women prefer men who have slightly taller than they are. It has possible that for most women there have a certain minimal threshold of height, after which they will consider a male as a potential sex partner. Thus men above that height will end up with similar numbers of sex partners. With regard to women, underweight women had notably fewer partners than other women. There are numerous possibilities as to why underweight women had few partners," explained Frederick. They may be highly dissatisfied with their weight and suffering from anorexia and thus not motivated to show their bodies. Additionally, being underweight is associated with a relatively high mortality rate and/or they could be suffering from a variety of ailments that cause weight loss and thus have fewer sex partners because they are dealing with serious health issues."

\section{References}

1. Rahul Hajare (2020). Scientology applied to the workday of women feels just as good as sex: Non clinical examination of less sunlight habit Pharmacy Institute in Pune University. Journal of Dermatology Research Reviews \& Reports. SRC/JDMRS/101.

2. Rahul Hajare. (2019). Non-Medical Basis Characterization of Orgasm Associated with Approach Sex Can Last up to 20 Seconds to 15 Minutes, Eligible Women Individuals' Poor Transportation Facility of Private Pharmacy Institutions in Pune, India. Open Acc J Oncol Med 3(3)- OAJOM.MS.ID.000162. DOI.

3. Rahul Hajare. (2019). An Important Study for Care Perspective Tops Self-Reported Private Co- Educational By Pass Pharmaceutical Institutions in Number of Abandoned Children. J Gynecol Women's Health.: 16(4): 555943. DOI: 10.19080/JGWH.2019.16.555943002.

4. Rahul Hajare, (2018).Unsafe sex: An emerging problem? J Gastrointest Dig Syst.

5. Rahul Hajare, (2019). Why non-naked family produce ape baby: To explore the aspect of cheeks pulp. Adv Bioeng Biomed Sci Res, Volume 2 | Issue 3 | 1 of 2. 